\title{
Thonon-les-Bains - Chemin de Marclaz dessus
}

Opération préventive de diagnostic (2013)

\section{Christophe Landry}

\section{(2) OpenEdition \\ Journals}

Édition électronique

URL : https://journals.openedition.org/adlfi/14962

ISSN : 2114-0502

Éditeur

Ministère de la Culture

Référence électronique

Christophe Landry, «Thonon-les-Bains - Chemin de Marclaz dessus » [notice archéologique], ADLFI.

Archéologie de la France - Informations [En ligne], Auvergne-Rhône-Alpes, mis en ligne le 29 mai 2015, consulté le 28 juillet 2021. URL : http://journals.openedition.org/adlfi/14962

Ce document a été généré automatiquement le 28 juillet 2021.

(c) ministère de la Culture et de la Communication, CNRS 


\section{Thonon-les-Bains - Chemin de Marclaz dessus}

Opération préventive de diagnostic (2013)

\section{Christophe Landry}

\section{NOTE DE L'ÉDITEUR}

Organisme porteur de l'opération : Inrap

1 Le diagnostic en préalable à l'extension d'une Zac a permis de mettre au jour, sur un terrain de $7740 \mathrm{~m}^{2}$, quelques témoins de l'exploitation agricole de la ferme moderne voisine. Il s'agit de drains et de fosses de plantation d'arbres, ainsi que d'un dépotoir renfermant de nombreux outils et récipients datant de la fin du XIX ${ }^{\mathrm{e}} \mathrm{s}$. et du début du $\mathrm{xx}^{\mathrm{e}} \mathrm{s}$. Un abondant lot de céramique a ainsi été prélevé, qui permet d'étoffer le corpus référentiel pour le Bas-Chablais à l'époque contemporaine. La terrasse tardiwürmienne apparaît entre $0,2 \mathrm{~m}$ et $1,05 \mathrm{~m}$ de profondeur selon les sondages, par endroit recouverte de colluvions récentes. Aucun témoin d'une occupation plus ancienne n'est à mentionner sur les parcelles concernées par le projet d'aménagement. 


\section{INDEX}

lieux https://ark.frantiq.fr/ark:/26678/pcrtSEeAipsBlD, https://ark.frantiq.fr/ark:/26678/ crtB8WDyqd6u9, https://ark.frantiq.fr/ark:/26678/pcrt5V2VjpTJWV, https://ark.frantiq.fr/ark:/ 26678/pcrt8fR8mwy7yM

nature https://ark.frantiq.fr/ark:/26678/pcrtWWQS75V5Bc

chronologie https://ark.frantiq.fr/ark:/26678/pcrtPSEEZSBEJp

Année de l'opération : 2013

sujets https://ark.frantiq.fr/ark:/26678/pcrt1DMOWvDF4j, https://ark.frantiq.fr/ark:/26678/

pcrtxs8Kml8jLw, https://ark.frantiq.fr/ark:/26678/pcrtfv4IrNiWE8

\section{AUTEURS}

\section{CHRISTOPHE LANDRY}

Inrap 